Rabaska

Revue d'ethnologie de l'Amérique française

\title{
Musée de la civilisation
}

\section{Agnès Dufour}

Volume 5, 2007

URI : https://id.erudit.org/iderudit/019072ar

DOI : https://doi.org/10.7202/019072ar

Aller au sommaire du numéro

Éditeur(s)

Société québécoise d'ethnologie

ISSN

1703-7433 (imprimé)

1916-7350 (numérique)

Découvrir la revue

Citer ce document

Dufour, A. (2007). Musée de la civilisation. Rabaska, 5, 244-245.

https://doi.org/10.7202/019072ar

Ce document est protégé par la loi sur le droit d'auteur. L'utilisation des services d'Érudit (y compris la reproduction) est assujettie à sa politique d'utilisation que vous pouvez consulter en ligne.

https://apropos.erudit.org/fr/usagers/politique-dutilisation/
Cet article est diffusé et préservé par Érudit.

Érudit est un consortium interuniversitaire sans but lucratif composé de l'Université de Montréal, l'Université Laval et l'Université du Québec à Montréal. Il a pour mission la promotion et la valorisation de la recherche. https://www.erudit.org/fr/ 
Le 16 juin 2007, on inaugurait le chantier de l'Histoire en devenir avec l'exposition Une page d'histoire en 2 tableaux, sur les belles années du Festival folklorique de 1967 à 1975 de Baie-Saint-Paul. C'est l'auteur et commissaire, Cyril Simard, président de la Société ÉCONOMUSÉE du Québec et président du comité organisateur de l'événement, qui le présenta. Le premier tableau célèbre les 40 ans d'effervescence culturelle à Baie-Saint-Paul depuis la naissance du festival folklorique et du Centre culturel en 1967. Le second tableau, en collaboration avec la Société ÉCONOMUSÉE et le Musée du costume et des textiles du Québec, offre un espace ouvert qui explore « la belle ouvrage de nos ancêtres ».

\section{Publication}

Les Presses de l'Université Laval ont récemment publié les actes du colloqueatelier Journalisme et patrimoine mondial, placé sous la direction de Charles Moumouni, professeur au département d'information et communication, et de Cyril Simard, premier titulaire de la chaire UNESCO en patrimoine culturel de cette institution. Cet ouvrage est le fruit de l'atelier international qui s'est tenu à l'Université Laval du 23 au 30 mai 2005, où « universitaires, experts, gestionnaires et usagers du patrimoine [firent] acquérir aux journalistes la compétence et la conscience de la fragilité du patrimoine et la nécessité de le préserver pour les générations futures avant que l'irréversible ne soit atteint ». L'atelier regroupait vingt-cinq participants, surtout des journalistes, œuvrant au sein d'entreprises de presse francophones, de douze nationalités et trois régions différentes (Afrique, États arabes et Europe-Amérique du Nord).

CARMEn D'EnTREMONT

\section{Musée de la civilisation}

16 , rue de la Barricade

Téléphone : (418) 528-2358

C.P. 155, succursale B

Sans frais : (866) 710-8031

Québec (Québec) G1K 7A6

Télécopieur : (418) 646-9705

Courrier : mcq@mcq.org

Toile : www.mcq.org

Le Centre de la francophonie des Amériques

Le Gouvernement du Québec a décidé de loger le Centre de la francophonie des Amériques au Musée de l'Amérique française, situé sur le site historique du Séminaire de Québec. L'implantation du Centre de la francophonie des Amériques dans ce haut lieu historique permettra aux deux organismes de 
devenir sans conteste une plaque tournante de la francophonie en Amérique. Le Musée de l'Amérique française ayant une vocation historique et le Centre de la francophonie étant tourné vers la promotion de la francophonie actuelle, leurs activités seront donc complémentaires. De plus, la proximité des deux institutions ne pourra que renforcer l'une et l'autre et permettra une plus grande synergie de leurs actions.

\section{Le legs de la France pour le $400^{\circ}$ anniversaire de Québec}

Projet architectural et muséal de grande ampleur, l'aménagement du Centre de la francophonie des Amériques du Musée de l'Amérique française constitue le cœur de la participation française. Le projet, tout en veillant à la fois à l'identification singulière du Musée de l'Amérique française et du Centre de la francophonie des Amériques, mettra en exergue les liens qui les unissent, donnant à la francophonie en Amérique une forte symbolique, traduisant entre autres l'amitié entre les peuples français et québécois.

Cette contribution comprend également un deuxième volet, sous la forme d'une exposition sur le thème « Des familles souches et des lieux de mémoires à la coopération des territoires », présentée au Musée de la civilisation dans un espace de $800 \mathrm{~m}^{2}$. Les principaux éléments de l'exposition seront, après 2008, installés au Musée de l'Amérique française et dans les autres espaces appartenant au Musée de la civilisation. Un conseil scientifique est chargé de préparer et de valider le contenu scientifique de cette exposition qui ouvrira ses portes en mai 2008 .

\section{Le Fonds du Séminaire de Québec reconnu par l'UNESCO}

À l'instar de précieux documents témoins des grandes étapes de l'histoire de l'homme à travers les siècles, telles la Déclaration des droits de l'Homme et du citoyen, la Bible de Gutenberg, la symphonie $n^{\circ} 9$ de Beethoven, les archives du ghetto de Varsovie, le Fonds du Séminaire de Québec, 16231800 , est maintenant inscrit au prestigieux registre du programme Mémoire $d u$ monde de l'Unesco. Le Fonds du Séminaire de Québec est constitué de nombreux documents d'une valeur historique inestimable puisqu'il témoigne de la migration, de l'implantation, de la continuité et du rayonnement de la culture française et de la spiritualité catholique en Amérique du Nord. Il confirme également le rôle déterminant de Québec (inscrite depuis 1985 à la liste du patrimoine mondial) dans les échanges entre l'Ancien et le Nouveau monde. C'est la toute première fois que des éléments du patrimoine documentaire canadien sont reconnus par cette instance internationale. Le Fonds du Séminaire y figure maintenant avec les archives de la Compagnie de la baie d'Hudson qui viennent d'y être inscrites. 